UNIVERSIDADE DE SÃO PAULO

INSTITUTO DE PSICOLOGIA

CRISTIANE CINTRA BRENTAN

\title{
A criatividade de crianças asmáticas
}

SÃO PAULO

2014 


\section{A criatividade de crianças asmáticas}

Versão corrigida

Dissertação apresentada ao Instituto de Psicologia da Universidade de São Paulo para obtenção do título de Mestre em Psicologia.

Área de concentração: Psicologia Escolar e Desenvolvimento Humano.

Orientadora: Profa. Dra. Audrey Setton Lopes de Souza

São Paulo 
AUTORIZO A REPRODUÇÃO E DIVULGAÇÃO TOTAL OU PARCIAL DESTE TRABALHO, POR QUALQUER MEIO CONVENCIONAL OU ELETRÔNICO, PARA FINS DE ESTUDO E PESQUISA, DESDE QUE CITADA A FONTE.

Catalogação na publicação Biblioteca Dante Moreira Leite

Instituto de Psicologia da Universidade de São Paulo

Brentan, Cristiane Cintra.

A criatividade de crianças asmáticas / Cristiane Cintra Brentan; orientadora Audrey Setton Lopes de Souza. -- São Paulo, 2014.

$236 \mathrm{f}$.

Dissertação (Mestrado - Programa de Pós-Graduação em Psicologia. Área de Concentração: Psicologia Escolar e do Desenvolvimento Humano) - Instituto de Psicologia da Universidade de São Paulo.

1. Criatividade 2. Asma 3. Psicossomática

4. Psicanálise 5. Winnicott, Donald Woods, 1896-1971 I. Título. 
BRENTAN, C. C. A criatividade de crianças asmáticas. Dissertação apresentada ao Instituto Psicologia da Universidade de São Paulo para obtenção do título de Mestre em Psicologia.

Aprovada em:

Banca Examinadora

Prof. Dr. instituição:

Julgamento: assinatura:

Prof. Dr. instituição:

Julgamento: assinatura:

Prof. Dr. instituição: assinatura: 
A meu querido marido Rogério, com amor, admiração e gratidão por seu carinho, presença e generosa dedicação no período de elaboração deste trabalho. À minha querida filha Laura, quem me tornou mãe, levando-me por caminhos até então desconhecidos durante a realização do Mestrado. 


\section{Agradecimentos}

Aos participantes da pesquisa, devo meu maior agradecimento. Sem eles, não teria tido acesso a todo o material necessário para a realização desta pesquisa.

À Prof. a Dr. a Audrey Setton Lopes de Souza, quem, com sua delicadeza e acolhimento, orientou-me e ajudou-me a olhar com profundidade as sutilezas do fenômeno psíquico, iniciando-me no gratificante caminho de pesquisadora.

À Prof. Tânia Corrallo Hammoud, com quem tive o privilégio trocar minuciosamente ideias sobre cada caso estudado, cujo conhecimento profundo sobre a teoria winnicottiana foram de grande riqueza.

Ao Prof. Dr. Joaquim Carlos Rodrigues, chefe do departamento de Pneumologia Pediátrica do Instituto da Criança do Hospital das Clínicas da Faculdade de Medicina da Universidade de São Paulo (HCFMUSP), quem tão prontamente permitiu a realização desta pesquisa no ambulatório de pneumologia pediátrica. E a todos os médicos e técnicos do departamento que me ajudaram muito me encaminhando os pacientes, apoio fundamental para a realização desta pesquisa.

À Prof. ${ }^{a}$ Ms. Sylvia Lúcia de Freitas da Escola de Educação Física da Universidade de São Paulo, quem permitiu que eu realizasse a pesquisa com seus alunos da turma de educação física para crianças asmáticas ajudando muito na coleta de dados.

À Prof. ${ }^{a}$ Dr. ${ }^{a}$ Ivonise Fernandes da Motta e a Prof. ${ }^{a}$ Dr. ${ }^{a}$ Helena Rinaldi Rosa, as quais fizeram parte do meu exame de qualificação e contribuíram profundamente para o desenvolvimento desta pesquisa.

À Prof. ${ }^{a}$ Dr. ${ }^{a}$ Iraí Cristina Boccato Alves, quem, com dedicação, sempre esteve presente orientando-me e dando apoio antes e durante a realização deste trabalho.

Ao Prof. Davy Bogomoletz, com quem tive o privilégio de trocar algumas ideias contribuindo imensamente com seu profundo conhecimento da teoria winnicottiana.

À Prof. ${ }^{a}$ Dr. ${ }^{a}$ Solange Wechsler, quem me recebeu tão acolhedoramente, indicando alguns caminhos a percorrer dentro do tema da criatividade.

Aos colegas do grupo de orientação, pelas trocas e apoio mútuo.

À Capes, pelo apoio financeiro.

Aos amigos e colegas que me apoiaram nesta caminhada.

Aos meus pais, sempre. 
Venha para o mundo de uma forma criativa, crie o mundo, só o que você criar terá sentido para você.

Winnicott, D.W. 


\section{Resumo}

BRENTAN, C. C. A criatividade de crianças asmáticas. 2014. 236 f. Dissertação de Mestrado. Instituto de Psicologia, Universidade de São Paulo USP, São Paulo, 2014.

A presente pesquisa avaliou a expressão da criatividade de crianças asmáticas, buscando relacioná-la a aspectos de sua personalidade. Existe uma suspeita de que alguns destes aspectos inibem a expressão da criatividade dessas crianças. A asma é um bom exemplo de doença psicossomática. Referências bibliográficas apontam para a observação de um funcionamento atípico do aparelho psíquico dos pacientes somáticos, caracterizado por uma carência funcional das atividades fantasmáticas ligadas à imaginação e à expressão simbólica. Neste contexto, o objetivo do estudo é compreender a relação existente entre a dinâmica da personalidade e a expressão da criatividade de crianças asmáticas. Utilizou-se um método de pesquisa qualitativa. A amostra foi composta de um grupo de quatro crianças, com faixa etária de 7 a 10 anos, portadoras de diagnóstico médico de asma brônquica moderada ou grave. A pesquisa foi realizada em crianças que estavam sendo atendidas no ambulatório de pneumologia pediátrica do Instituto da Criança do Hospital das Clínicas da Faculdade de Medicina da Universidade de São Paulo. Primeiramente, foi apresentado aos pais o termo de consentimento. Foi feita uma entrevista semiestruturada com os pais e realizados dois encontros com a criança, para a aplicação do Procedimento do Desenho-Estória e do Teste de Criatividade Figural Infantil, finalizando com uma entrevista devolutiva para os pais e para a criança e totalizando quatro encontros. Dois conceitos distintos de criatividade foram abordados na pesquisa: a criatividade a que se refere a teoria winnicottiana, teoria escolhida para fazer a leitura psicológica dos sujeitos de pesquisa, e a criatividade a que se refere o Teste de Criatividade Figural Infantil. Como resultado da pesquisa, percebeu-se que não foi possível encontrar um perfil psicológico da criança asmática, visto que as quatro crianças da amostra apresentaram aspectos da personalidade muito peculiares, havendo também peculiaridades nas expressões de suas criatividades. Por outro lado, foi possível perceber a relação individual da personalidade de cada criança com a expressão de sua criatividade, podendo-se fazer uma comparação entre elas. $\mathrm{O}$ estudo apontou que, em geral, a criança asmática consegue expressar sua criatividade, não corroborando estudos anteriores ligados à psicossomática. Além disto, a presente pesquisa deu indícios de que o indivíduo que consegue vivenciar o espaço potencial de maneira saudável pode apresentar um alinhamento percebido entre os dois conceitos de criatividade abordados no estudo.

Palavras-chave: criatividade; asma; psicossomática; psicanálise; Winnicott, D.W. 


\begin{abstract}
BRENTAN, C. C. The asthmatic children's creativity. 2014. 236 f. Master Thesis. Instituto de Psicologia, Universidade de São Paulo USP, São Paulo, 2014.

The present study has evaluated the creativity expression of children with asthma, seeking to relate it to aspects of their personality. There is a suspicion that some of these aspects inhibit the expression of these children creativity. Asthma is a good example of psychosomatic illness. References point to the observation of atypical functioning of somatic patients' psychic apparatus, described as a functional deficiency of the ghostly activities related to imagination and symbolic expression. In this context, the study's goal is to understand the relationship between the personality dynamics and the asthmatic children's creativity. There was adopted a qualitative research method. The sample consisted of a four children group, aged 7-10 years, with a diagnosis of moderate or severe bronchial asthma. The field research was performed with children who have been treated at the pediatric pulmonology department at Instituto da Criança do Hospital das Clínicas da Faculdade de Medicina da Universidade de São Paulo. At first, there was submitted a consent form to the parents. Then, there were performed a semi-structured interview with the parents and two meetings with each child, dedicated to the Procedure of Drawing-Story and the Children's Creativity Figural Test, ending with a feedback interview with parents and child and totalizing four meetings with each research subject. Two distinct concepts of creativity were addressed in this study: creativity referred to Winnicott's theory, theory chosen to make the psychological reading of the research subjects, and creativity referred to Test of Creativity Figural Child. A result of the research is that it was not possible finding a psychological profile of the asthmatic children as the four children in the sample had very peculiar aspects of personality, with peculiarities in the expressions of their creativity as well. On the other hand, there was observed an individual relationship of each child's personality with the expression of their creativity, reasonably allowing making a comparison between them. The study found that, in general, asthmatic children can express their creativity, not confirming previous studies related to psychosomatic. Moreover, this research has hinted that an individual who healthily experiences the potential space could present a perceived alignment between both creativity concepts addressed in the study.
\end{abstract}

Keywords: creativity; asthma; psychosomatic; psychoanalysis; Winnicott, D. W. 


\section{APRESENTAÇÃO}

Este estudo surgiu do entrelaçamento de questões pessoais e profissionais e do meu interesse nas áreas de Psicologia e Artes Plásticas, razões que me levaram a pesquisar a relação entre os aspectos dinâmicos da personalidade e a expressão da criatividade de crianças asmáticas. Sou Psicóloga Clínica e atendo em consultório particular, realizando tratamento psicoterápico de crianças e adultos. Formada também em Artes Plásticas pela Escola de Belas Artes da Universidade Federal do Rio de Janeiro, utilizo, em consultório, técnicas expressivas e lúdicas, como forma de acessar conteúdos muitas vezes difíceis de serem acessados pela linguagem oral.

No atendimento a crianças, as técnicas lúdicas e expressivas são muito utilizadas. No brincar, a criança se expressa e se comunica. A criatividade sempre está presente na forma como a criança interage e cria suas brincadeiras, seus desenhos, suas pinturas e outras formas de expressão.

Tenho dedicado especial interesse à observação de como as crianças asmáticas se comunicam com o mundo e como elas expressam sua criatividade. A literatura traz referências que associam os aspectos da dinâmica da personalidade com a expressão da criatividade, além de algumas pesquisas que apontam características peculiares da personalidade de crianças com asma. A asma tem sido tratada, por diversas abordagens, como uma doença psicossomática.

Neste contexto, algumas questões vêm motivando meu interesse e pretendo investigálas em minha Dissertação de Mestrado. São elas:

- Como é a expressão da criatividade na criança com asma? (A asma é caracterizada por uma dificuldade em respirar. A respiração é uma troca constante com o mundo. A criança inspira e expira - ao expirar, expressa-se no mundo.)

- Qual a característica peculiar que se pode perceber na expressão da criatividade da criança asmática?

- A expressão da criatividade de crianças asmáticas tem relação com os aspectos de sua personalidade? 
Estas perguntas e a lembrança de ter sido uma criança asmática motivam-me e suscitam este estudo.

Alguns autores afirmam que fatores emocionais e ambientais contribuem para o aparecimento da asma. Dentre eles, Macedo de Queiroz e Strauss (1958) citou, como fatores que influenciam diretamente o desencadeamento de crises asmáticas em crianças, as emoções fortes e a sensação de perda de afeto. Os fatores de influência indiretos que foram verificados pelos citados autores são referentes ao ambiente emocional do lar e as atitudes educacionais inadequadas, como por exemplo, conflitos constantes entre os familiares e a superproteção dos pais, os quais repercutiam na personalidade da criança, aumentando suas tensões e intensificando o quadro asmático. Os citados autores relacionaram, também, problemas de comportamento do próprio paciente - tais como agressividade, dependência, ansiedade e distúrbios da alimentação - como desencadeadores de crise.

A literatura aponta a relevância da utilização de técnicas projetivas na investigação da personalidade. Pode-se destacar o estudo realizado por Lourenção van Kolck e Moraes Jaehn (1982), o qual verificou, por meio da projeção da imagem corporal nos Desenhos da Figura Humana criados por crianças asmáticas, que o pescoço e o tronco revelam-se áreas focais de conflito, evidenciando a importância psicológica dessas regiões do corpo para essas crianças. Nos sujeitos, também incidiram traços de imaturidade, o que corrobora resultados de diversos estudos.

Buscando aprofundamento nas citadas observações empíricas de modo a responder às questões que motivaram o estudo, este projeto de pesquisa visa compreender a relação existente entre os aspectos da dinâmica da personalidade e a expressão da criatividade de crianças asmáticas. Primeiramente será feita uma revisão bibliográfica enfocando a asma e seus aspectos psicossomáticos, bem como abordando os conceitos apresentados pela teoria de Winnicott e pela Escola Psicossomática de Paris. Posteriormente, será descrito o conceito de criatividade utilizado no estudo, tendo por base a teoria Psicanalítica, que contribuirá também para a análise e a interpretação dos resultados obtidos na pesquisa.

Serão utilizados, como instrumentos de pesquisa:

(i) uma entrevista semiestruturada dirigida aos pais do sujeito de pesquisa, a qual visa verificar alguns aspectos da história familiar da criança asmática que podem ter influenciado no seu desenvolvimento psíquico, assim como no aparecimento do sintoma; 
(ii) o Procedimento de Desenho-Estória (D-E), com o objetivo de avaliar aspectos da personalidade da criança com asma;

(iii) o Teste de Criatividade Figural Infantil (TCFI), para avaliar a expressão da criatividade destas crianças.

Para o exame de Qualificação, foi apresentado um estudo de caso, o qual foi realizado como piloto para a testagem dos instrumentos de pesquisa, visando contribuir para a qualidade metodológica do estudo. 


\section{ANÁLISE DOS DADOS:}

A tabela 1, a seguir, traz um resumo dos resultado obtidos nas entrevistas, nos procedimentos dos Desenho-Estórias e dos Testes de Criatividade dos sujeitos constituintes da amostra. Sua leitura facilita a percepção de padrões e a conclusão sobre as descobertas descritas em seguida.

Tabela 1: Resumo dos resultados

\begin{tabular}{|c|c|c|c|c|c|}
\hline \multicolumn{2}{|c|}{ Resultados para os Sujeitos } & \multirow{2}{*}{\begin{tabular}{l}
\multicolumn{1}{c}{ Elias } \\
$\begin{array}{l}\text { Dificuldade de } \\
\text { transitar e de contato } \\
\text { com o mundo } \\
\text { objetivo, vive uma } \\
\text { indiferenciação }\end{array}$
\end{tabular}} & \multirow{2}{*}{$\begin{array}{l}\text { Sílvio } \\
\\
\text { gue transitar e } \\
\text { ue diferenciar }\end{array}$} & \multirow{2}{*}{$\begin{array}{l}\quad \text { Amanda } \\
\\
\text { Consegue transitar } \\
\text { e consegue } \\
\text { diferenciar }\end{array}$} & \multirow{2}{*}{\begin{tabular}{l}
\multicolumn{1}{c}{ Natália } \\
$\begin{array}{l}\text { Dificuldade de } \\
\text { transitar, e de contato } \\
\text { com mundo } \\
\text { subjetivo }\end{array}$
\end{tabular}} \\
\hline D-E & $\begin{array}{l}\text { Transição entre } \\
\text { mundo subjetivo e } \\
\text { objetivo }\end{array}$ & & & & \\
\hline & $\begin{array}{l}\text { Criatividade para } \\
\text { teoria winnicottiana }\end{array}$ & $\begin{array}{l}\text { Expressão criativa } \\
\text { comprometida }\end{array}$ & $\begin{array}{l}\text { Tem expressão } \\
\text { criativa }\end{array}$ & $\begin{array}{l}\text { Tem expressão } \\
\text { criativa }\end{array}$ & $\begin{array}{l}\text { Expressão criativa } \\
\text { comprometida }\end{array}$ \\
\hline \multirow{5}{*}{ TCFI } & $\begin{array}{l}\text { Fator 1: Enriqueci- } \\
\text { mento de ideias }\end{array}$ & 89: Superior & 59: Média & 72: Acima da média & 24: Abaixo da média \\
\hline & $\begin{array}{l}\text { Fator 2: } \\
\text { Emotividade }\end{array}$ & 40: Média & 96: Superior & 91: Superior & 40: Média \\
\hline & $\begin{array}{l}\text { Fator 3: Preparação } \\
\text { Criativa }\end{array}$ & 55: Média & 63: Média & 4: Inferior & 22: Abaixo da média \\
\hline & $\begin{array}{l}\text { Fator 4: Aspectos } \\
\text { Cognitivos }\end{array}$ & 94: Superior & 68: Acima da média & 11: Inferior & 38: Média \\
\hline & $\begin{array}{l}\text { Fator Geral } \\
\text { Resultante }\end{array}$ & 92: Superior & 69: Acima da média & 45: Média & 28: Abaixo da média \\
\hline \multirow{4}{*}{ Entrevista } & Desmame & Prolongado e difícil & $\begin{array}{l}\text { Talvez um pouco } \\
\text { precoce }\end{array}$ & Prolongado & Prolongado e difícil \\
\hline & Mãe & $\begin{array}{l}\text { Distante do mundo } \\
\text { subjetivo do filloo }\end{array}$ & $\begin{array}{l}\text { Distante do mundo } \\
\text { subjetivo do filho }\end{array}$ & $\begin{array}{l}\text { Distante do mundo } \\
\text { subjetivo da filha }\end{array}$ & $\begin{array}{l}\text { Distante do mundo } \\
\text { subjetivo da filha }\end{array}$ \\
\hline & Expressão Verbal & $\begin{array}{l}\text { Extremamente } \\
\text { inseguro }\end{array}$ & $\begin{array}{l}\text { Inseguro, adquiriu } \\
\text { confiança no decorrer } \\
\text { das atividades }\end{array}$ & Insegura e tímida & $\begin{array}{l}\text { Confiante, porém } \\
\text { buscando o } \\
\text { confronto }\end{array}$ \\
\hline & $\begin{array}{l}\text { Diagnóstico de } \\
\text { Asma }\end{array}$ & $\begin{array}{l}\text { Grave e de difícil } \\
\text { controle }\end{array}$ & Leve e controlada & $\begin{array}{l}\text { Moderada, controle } \\
\text { parcial }\end{array}$ & $\begin{array}{l}\text { Moderada, controle } \\
\text { parcial }\end{array}$ \\
\hline
\end{tabular}


Após a análise individual de cada caso e dos dados tabulados, alguns aspectos gerais podem ser considerados:

i. Não foi verificado, como se esperava e tal como algumas pesquisas apontavam, que crianças portadoras de alguma doença psicossomática, como por exemplo a asma, teriam um empobrecimento da vida imaginária, simbólica e criativa. As crianças da amostra conseguiram se expressar simbolicamente, criando estórias e desenhos.

ii. Tanto o Teste de Criatividade Figural Infantil quanto o Procedimento de DesenhosEstória se mostraram sensíveis para avaliar a criatividade. No entanto, na análise do material, o Teste se detém mais aos aspectos de nível quantitativo, enquanto os desenhos-estória são mais sensíveis para analisar aspectos qualitativos relacionados a aspectos da dinâmica emocional, permitindo explorar em que medida tal criatividade pode ser entendida como a expressão de um viver criativo na concepção winnicottiana, diferenciando modos mais subjetivos ou mais objetivos de viver o mundo. Os dois instrumentos utilizados conjuntamente tiveram um resultado bastante interessante, obedecendo a uma certa gradação e correspondência, as quais serão discutidas mais adiante.

iii. A entrevista mostrou-se um instrumento de pesquisa sensível para avaliar a relação das crianças com suas mães, sendo possível entender um pouco melhor a dinâmica das relações familiares. Foi possível observar uma certa dificuldade de separação da maioria das mães, além de uma dificuldade destas para entrar em contato com o mundo subjetivo dos seus filhos.

Observando-se detidamente os dados, pode-se perceber alguns elementos que se destacam. As análises foram feitas com o auxílio de tabelas comparativas presentes nos anexos (ANEXO T, ANEXO U, ANEXO V, ANEXO W, ANEXO X, ANEXO Y):

- Em pelo menos três casos, repetiram-se dificuldades das mães em procurar tratamento para os filhos logo que surgiram os episódios de asma; a maioria delas esperou a doença evoluir para, só então, começar um atendimento mais cuidadoso. Pode-se pensar em uma dificuldade destas mães em estarem disponíveis, mais atentas, buscando um cuidado mais imediato.

- Nestes mesmos três casos pôde ser observada uma certa dificuldade na realização do desmame, um pouco mais estendido do que o período necessário para a amamentação. 
No início do desmame, a criança precisa entrar em contato com a frustração. A falha da mãe esperada neste momento está ligada ao fato de permitir um distanciamento e a frustração do bebê. Parece ter havido um período de hesitação das mães neste momento em que o bebê começa a se separar dela, indo para o mundo, desmamando. O bebê precisa, nesta fase, fazer movimentos em direção ao mundo objetivo, retornando para o mundo subjetivo, sendo desta forma encorajado pela mãe em se lançar nesta experiência de vida. As mães do Elias, da Natália e da Amanda, parecem hesitar neste momento, prolongando a amamentação. Agiram diferentemente da mãe do Sílvio, quem parece vivenciar o desmame de uma maneira mais natural, concluindo o desmame aos seis meses de idade e iniciando a papinha aos quatro meses de idade. No entanto, assim como as outras mães, ela parece ter uma dificuldade de envolver-se com o mundo subjetivo de seu filho, fazendo pensar se este desmame pode não ter sido natural para o bebê - ele pode não ter acompanhado o ritmo.

- As mães do Elias, da Natália e da Amanda parecem ter um comportamento ambíguo, continuam amamentando mas não queriam mais estar amamentando, perecendo vivenciar um conflito, uma dificuldade de propiciar este distanciamento, permaneciam presentes corporalmente, não estando presentes subjetivamente. Já a mãe do Sílvio pode ter tido um comportamento mais distante, porém precocemente.

Na observação de bebês em uma situação padronizada, na qual Winnicott (2000) descreve os estágios do comportamento do bebê no jogo das espátulas, é possível, verificar no estágio denominado pelo autor como 'período de hesitação', que a hesitação é algo vivenciado pelo bebê. A hesitação é normal, dependendo do grau e da qualidade. No entanto, pode-se pensar que, se a mãe vive uma hesitação acentuada, ou não está lá para dar suporte, pode haver também, por parte do bebê, um agravamento desta hesitação, pois ele não encontra ao seu lado a mãe ou o ambiente que lhe acolhe e lhe encoraja - pelo contrário, é um ambiente que hesita, que está inseguro e, sendo assim, o bebê pode paralisar-se diante da exploração do mundo, tendo dificuldade de lançar-se na exploração do objeto, como Winnicott (2000) descreve no jogo das espátulas.

É possível conjeturar que a asma tem a ver com respiração e respiração tem a ver com tempo, ritmo, troca com o ambiente. Ao se preparar para uma situação que exija coragem, parece natural que se encha os pulmões de ar para encarar um certo risco e o medo do 
desconhecido. Se for possível encarar esta situação de uma forma confiante, esta troca com o ambiente fluirá, o ar sairá dos pulmões e completará o seu ciclo. Mas, se existe muito medo ou uma paralisação diante da situação, o ar dentro dos pulmões também é paralisado, o ar não sairá para o ambiente, ficando preso internamente nos pulmões e não permitindo a entrada de mais ar. É isto que acontece com a asma, não é uma falta de ar, na qual a pessoa não consegue inspirar e, sim, um excesso de ar nos pulmões que a pessoa não consegue expelir, expressar-se e trocar com o ambiente.

As necessidades do bebê acontecem em um tempo, em um ritmo, num corpo em que tudo isto precisa estar integrado. Estas são as tarefas do bebê e as tarefas também de todos os adultos ao longo da vida. No entanto, para o bebê, elas são constitucionais. Isto precisa acontecer de forma muito afinada e atenta pelo ambiente, pela mãe. Quando o bebê chega no tempo de precisar se afastar, e abandonar a amamentação, é natural que aconteça em um ritmo de vai e vem, vai e vem, largando aos poucos o seio. Não é natural que ele largue o seio de uma vez, repentinamente, como aconteceu com dois sujeitos desta pesquisa, Elias e Natália, cuja amamentação é interrompida abruptamente quando tinham um ano e quatro meses de idade. O bebê precisa ir e vir do mundo e a mãe precisa estar sintonizada com isto, para respeitar esse tempo e esse ritmo.

A criatividade, do ponto de vista tal como é entendida pela psicanálise winnicottiana, tem a ver com a possibilidade de expressão espontânea e própria. E isto só acontece se houver um ambiente que vá apresentando o mundo e permitindo que essa criança viva neste mundo no ritmo e diante das necessidades supridas de cada fase do desenvolvimento, necessidades diferentes em cada momento de vida. Na hora de estar muito presente, estar muito presente e, na hora de se ausentar e propiciar as frustrações, também poder fazer isto.

Pode-se inferir dos resultados da pesquisa, que faz sentido pensar na possibilidade de associação da asma com alguma dificuldade da mãe no momento dessa transição do bebê do mundo subjetivo para o mundo objetivo, no sentido tanto desta mãe poder estar próxima na hora que a criança precisa, quanto de não estar quando a criança não precisa.

Em um determinado momento, até mais ou menos o momento da amamentação, a mãe precisa estar lá incondicionalmente. No entanto, a partir de um determinado momento, tanto ela quanto o bebê precisam, por necessidades próprias, afastar-se. E este é o momento de entrada da possibilidade da falha: esta mãe precisa ir falhando gradativamente para que esse bebê consiga fazer o desmame e todos os desmames que vêm junto. E, neste momento em que 
a possibilidade de contato objetivo com o mundo precisa ser mediado pela mãe, ela deve falhar numa dosagem em que esteja ausente e esteja presente na medida da necessidade do bebê.

O bebê só pode sair da sua visão onipotente inicial em que não existe a falha para um momento que que existe falha, se houver exatamente esse momento de transição, que pode ser representado pelo objeto transicional, algo real que fica no lugar da mãe, mas sobre o qual o bebê pode viver uma experiência de posse semelhante a que ele viveu no momento anterior onde ele e a mãe eram uma coisa só.

Para que a falha possa ser suportada, é preciso ter essa experiência de posse. Se a criança passou por essa experiência, de usar o objeto do jeito que quiser, e ter direito de posse sobre uma coisa que é real e sobre algo que é dele, ele consegue ir aguentando aos poucos os afastamentos as ausências e é isso que inaugura o espaço potencial, esse trânsito do mundo subjetivo para o mundo objetivo.

Entretanto, quando a criança se apega demais e por muito tempo a algo do próprio corpo, como por exemplo roer unha (caso do Sílvio, um dos sujeitos desta pesquisa), ela está sinalizando que alguma coisa nessa passagem não se deu da forma que ela necessitava, o contato com a realidade objetiva não se consolidou de uma forma muito tranquila. A manutenção da chupeta por muito tempo (caso do Elias), assim como o roer unha (caso do Sílvio), podem ser sinais de falhas nesta passagem.

Indícios de como a criança vive esse espaço potencial podem ser encontrados nessa relação entre a vivência do mundo subjetivo e do mundo objetivo, como se dá esta permeabilidade entre eles e a transição entre esses dois mundos. Isto parece ser um dado importante, o qual esteve presente durante a análise dos casos desta pesquisa.

Pôde-se observar, por exemplo, que Elias apresentou uma permeabilidade tão grande entre o mundo subjetivo e o mundo objetivo, que seus desenhos-estória, embora sejam muito criativos, parecem desprendidos de sentido, como se ele mesmo se perdesse e estivesse tentando se encontrar. Parece ser a criança mais desorganizada psiquicamente, no nível emocional. Foi ele também quem teve a criatividade mais alta no teste de Criatividade Figural Infantil, em um nível superior ao esperado para sua faixa etária. Contudo, do ponto de vista psicológico, ele é uma criança que está bastante desorganizada, vivendo uma certa indiferenciação entre o mundo subjetivo e o mundo objetivo. Pode-se inferir que a 
criatividade, no aspecto winnicottiano, associada ao verdadeiro self, a uma expressão espontânea, plena de significado individual e expressão da própria individualidade, está relativamente comprometida em Elias. Mesmo sendo ainda uma criança, na qual o amadurecimento está ocorrendo, há indícios de que ele não está se desenvolvendo de uma forma saudável. Pode-se considerar que o viver criativo, a criatividade do ponto de vista winnicottiano, está bastante comprometida, sendo um resultado oposto ao da criatividade de nível superior ao qual o teste se refere.

Este achado faz pensar em um paralelo entre a expressão do artista e sua saúde psíquica. Nem sempre o artista, por exemplo ao fazer uso da sua criatividade, está diante de um amadurecimento emocional correspondente. O uso que ele faz desta expressão muitas vezes tem a ver com uma busca de encontrar a sua criatividade original que ainda não foi alcançada, buscando a possibilidade de encontrar a si mesmo e tentando encontrar algo que não pode ser ainda experienciado. Nem sempre a criatividade artística é igual à maturidade emocional, como pode ser observado em algumas biografias de pessoas altamente criativas.

Elias parece usar sua criatividade, sua expressão nos desenhos-estória, como forma de buscar uma comunicação com o mundo, que faça com que o mundo entenda que esta passagem que ele está tentando fazer, de preservação de si mesmo e de contato com a realidade, sem se perder nem numa coisa nem noutra, ainda não aconteceu. Ele comunica isso, há coisas ainda muito desorganizadas dentro dele e ele usa isso como forma de expressão na sua plenitude, mais para expressar a sua imaturidade emocional. Ele não consegue se pôr no mundo de forma madura, ou seja, buscar uma conciliação entre o eu e o mundo, entre o subjetivo e o objetivo, sem desconsiderar nenhum dos dois lados.

Desta forma, na realização da análise da pesquisa, pode ser observada uma gradação e uma correspondência entre a expressão no desenho-estória e o teste de criatividade figural infantil, no seguinte sentido:

Elias foi a criança que apresentou maior confusão e permeabilidade entre o mundo subjetivo e o mundo objetivo, parecendo estar mais mergulhado no mundo subjetivo, apresentando uma certa indiferenciação e confusão em seus desenhos-estória, mas fazendo-os de forma bastante fácil, não apresentou dificuldades em criar os desenhos-estória. Foi o que apresentou a maior pontuação geral no teste de criatividade, sendo considerado um sujeito com criatividade de nível superior ao esperado. Por outro lado, foi a criança que apresentou 
menor organização psíquica e menor maturidade emocional, tendo uma criatividade do ponto de vista winnicottiano mais empobrecida.

Sílvio conseguiu produzir os desenhos-estória de forma tranquila, conseguiu criar estórias e personagens fictícios, sabendo diferenciar melhor que Elias o seu mundo subjetivo do mundo objetivo e conseguindo transitar entre estes dois mundos, criando desenhos e estórias. Teve uma pontuação acima da média no teste de criatividade.

Amanda conseguiu produzir os desenhos-estória com um pouco mais de dificuldade. Um pouco insegura, conseguiu transitar de forma um pouco mais tímida nesta área entre o subjetivo e o objetivo. Obteve pontuação média no teste de criatividade.

Natália foi a criança que teve mais dificuldade em fazer os desenhos-estória. Muito mais amparada ao mundo objetivo, quis copiar desenhos, e contou uma estória já existente e conhecida. Há uma dificuldade em transitar entre o mundo subjetivo e objetivo, por ser muito cautelosa em transitar no mundo subjetivo. Obteve pontuação abaixo da média no teste de criatividade. Assim como Elias, só que de maneira oposta, existe um comprometimento maior no nível emocional, pois tem mais dificuldade de entrar em contato com o subjetivo e o seu eu. Parece fixada em um falso Self, tendo um viver criativo mais empobrecido, por estar distanciada de seu mundo interior e subjetivo.

Sendo assim, a pesquisa apontou para o seguinte possibilidade: quem consegue lidar melhor dentro do espaço potencial, havendo uma interação entre o mundo subjetivo e objetivo, tem uma correspondência maior entre um desenvolvimento mais adequado em direção ao viver criativo do ponto de vista winnicottiano, possuindo também um bom nível de criatividade, como a que foi abordada no teste de Criatividade Figural Infantil.

Quem, de alguma forma está mais preso seja ao mundo subjetivo seja ao mundo objetivo e não consegue ter uma trânsito adequado na área do espaço potencial, mostra uma inadequação ao viver criativo. Caso esteja mais submerso no mundo subjetivo, pode apresentar uma criatividade superior no teste e, caso esteja muito mais preso ao objetivo, pode apresentar uma criatividade abaixo da média no teste. No entanto, nos dois casos, há um maior comprometimento do viver criativo, ou seja, menor criatividade do ponto de vista de winnicottiano.

Dentre as quatro crianças analisadas, não foi possível chegar-se a uma conclusão a respeito de aspectos da personalidade típicos da criança asmática, visto que cada uma delas 
tem uma expressão muito singular. Porém, foi verificado que, em todas elas, houve um aspecto que chamou atenção: o fato das mães apresentarem um certo distanciamento da vida subjetiva da criança e três delas também apresentarem no momento do desmame uma passagem do mundo subjetivo para o mundo objetivo um pouco mais dificultada pela amamentação muito prolongada (nos casos do Elias, da Amanda e da Natália), ou talvez retirada precoce da amamentação (no caso do Sílvio), corte abrupto na amamentação (no caso do Elias e da Natália), ao tirar a chupeta abruptamente (como no caso do Elias, que o pai jogou fora aos cinco anos de idade, dando início a roer unha), e a entrada na escola bastante postergada (como no caso da Amanda), dentre outros fatores. Este padrão parece confirmar o que Winnicott (2000) verificou no jogo de espátulas. A asma parece ilustrar corporalmente este medo de ir para o mundo, esta hesitação exagerada vivida pela criança. A mãe, quando um elemento confiável, capaz de estar atenta e sintonizada com as necessidades da criança, faz com que ela sinta-se segura para ir para o mundo, começar a brincar e explorar o desconhecido.

A característica principal da asma é não conseguir pôr o ar para fora. Nas crianças da pesquisa também foi verificado algo desta natureza. A expressão da fala de Elias foi muito baixa, e o tempo todo parece perguntar se realmente pode se expressar. O Sílvio inicialmente inseguro foi adquirindo confiança no desenrolar das atividades, entretanto expressou-se de forma extremamente controlada. Amada se mostrou muito tímida e insegura. Natália, quem foi a única que parecia expressar-se de forma fluída, pode ser percebida com uma expressão estereotipada, sem sentido e significado para seu próprio eu, buscando reproduzir fatos e estórias já conhecidas e pertencentes ao mundo objetivo.

A criança, para poder ir para o mundo que significa desmamar, significa andar, significa controlar os esfíncteres, significa usar o corpo de forma motora cada vez mais em direção ao mundo, para ela poder fazer isto, vai olhar para a mãe procurando apoio, percebendo se a mãe confia que ela pode ir, se a mãe sabe avaliar que aquilo que ela quer fazer não é perigoso. Se perceber uma hesitação por parte da mãe, ou que ela não está ali dando apoio, ou que a mãe tem medo, a criança vai hesitar por mais tempo e é na hesitação que surge a asma, segundo Winnicott (2000). E este aspecto foi corroborado por nossa amostra. Nesta hesitação, o ar fica preso e a expiração fica em suspenso, como se esperando o momento certo para concluir seu ciclo, como se tomasse fôlego para ir para o mundo. E, quando há a hesitação, o ar fica retido e não sai, a criança não consegue pôr o ar para fora e fazer a próxima inspiração. 
Algo que perpassa a compreensão inteira da teoria winnicottiana é que a pessoa só pode se sentir viva e, portanto, ter saúde, se for uma pessoa que está em paz consigo mesma, que está integrada, se é capaz de se relacionar com o mundo e com os ouros de uma forma produtiva em vários aspectos. Ao mesmo tempo, há que ser capaz de preservar a si mesma, sua individualidade e singularidade, partindo sempre do gesto espontâneo e podendo relacionar-se com o mundo, sentindo que algo daquilo que está acontecendo faz parte de você, vem de você e faz parte de você espontaneamente, estando, desta forma, mais sintonizada com sua expressão criativa. 


\section{CONSIDERAÇÕES FINAIS}

O objetivo da pesquisa era compreender a relação existente entre os aspectos da personalidade e a expressão da criatividade de crianças asmáticas. As quatros crianças da amostra apresentaram aspectos da personalidade muito peculiares, assim como houveram peculiaridades nas expressões de sua criatividade.

Foi possível perceber a relação individual da personalidade de cada criança com a expressão de sua criatividade, não sendo possível traçar-se um perfil de personalidade da criança asmática, corroborando a ideia de Kreisler (1999) que diz que a personalidade da criança asmática é de grande diversidade.

Pôde-se verificar, no estudo, que as crianças conseguiram expressar-se por meio dos dois instrumentos de pesquisa, o Procedimento do Desenho-Estória, e o Teste de Criatividade Figural Infantil, e foram de modo geral criativas, não corroborando com estudos ligados a doenças psicossomáticas que supõe certo empobrecimento da vida mental, carência de fantasias, de imaginação ou de expressão simbólica.

O que pôde ser observado, de modo geral, é que as relações familiares dos quatro sujeitos de pesquisa eram similares no que diz respeito à relação que a mãe estabelece com o filho, de um certo distanciamento do seu mundo subjetivo, ao mesmo tempo que parece existir uma dificuldade de separação. Isto poderia ser um fator que contribuiu para a hesitação mais acentuada da criança na exploração do mundo, podendo ter relação com a asma no aspecto de retenção do ar nos pulmões, como foi descrito mais detalhadamente no capítulo anterior, de análise dos dados.

Outro resultado alcançado foi a relação existente entre os dois conceitos distintos de criatividade a que o estudo se refere. Por meio dos resultados, foi possível observar que estes dois conceitos não têm uma relação diretamente proporcional. Houve um resultado inversamente proporcional e três resultados diretamente proporcionais. Contudo, do entendimento de como se organiza a personalidade da criança dentro da teoria winnicottiana, (no que diz respeito a como se estabelece a transicionalidade entre o mundo subjetivo e o mundo objetivo) é possível inferir o caminho da expressão criativa da criança: se esta expressão está em busca de maior amadurecimento psíquico, no sentido de precisar buscar mais maturidade e saúde emocional, ou está no caminho saudável de seu desenvolvimento e amadurecimento. 
Neste sentido, a pesquisa apontou para a possibilidade de que o indivíduo que consegue vivenciar o espaço potencial de forma mais saudável, conseguindo transitar entre o mundo subjetivo e objetivo, possui uma maior possibilidade de correlação entre os dois conceitos de criatividade, da teoria Winnicottiana e do Teste de Criatividade Figural Infantil. Caso contrário, a correspondência pode existir ou não.

Sendo assim, fazem-se necessárias novas pesquisas que busquem aprofundar as questões que foram levantadas na conclusão do atual estudo e possam suprir algumas das limitações próprias do método, como, por exemplo: a amostra pequena que não permite uma generalização das conclusões e a lida com características complexas de personalidade as quais trazem peculiaridades diversificadas necessitando de mais pesquisas. 


\section{REFERÊNCIAS}

ALEXANDER, F. Medicina psicosomatica. La Habana, Cultural, 1954.

BARROS, E.M.R e BARROS E.L.R. Significado de Melanie Klein. In: PINTO, M.C. (Org.) Livro de Ouro da Psicanálise. Rio de Janeiro: Ediouro, 2007. P.217-221.

BLEGER, J. Temas de psicologia: entrevista e grupos. - $3^{\mathrm{a}}$ ed. - São Paulo: Martins Fontes, 2007.

CALIA, M.M.M. No caminho da transicionalidade: brincando criamos o mundo. In: GUELLER, A.S.; SOUZA A.S.L. (Orgs.) Psicanálise com crianças: perspectivas teóricoclínicas. São Paulo: Casa do Psicólogo, 2008. P. 135-150.

CASTRO, L.R.F. Uma introdução à psicossomática da criança através do estudo funcional da asma. In: FERRAZ, F.C.; VOLICH, R.M.(Orgs.). Psicossoma I: Psicanalise e Psicossomática. São Paulo: Casa do Psicólogo, 2004. P. 131-148.

DEBRAY, R. Bebês: Mães em revolta. Porto Alegre: Artes Médicas, 1988.

O equilíbrio psicossomático: e um estudo sobre diabéticos. São Paulo: Casa do Psicólogo, 1995.

DIAS, E.O. A teoria do amadurecimento de D. W. Winnicott. Rio de Janeiro: Imago, 2003.

ELIA, L. Psicanálise: clínica \& pesquisa. In: ALBERTI, S.; ELIA, L. (Orgs.) Clínica e pesquisa em psicanálise. Rio de Janeiro: Rios Ambiciosos, 2000.

FREUD, S. Esboço de Psicanálise. Rio de Janeiro: Imago, 1974.

HISADA, Sueli. Conversando sobre Psicossomática. Rio de Janeiro: Revinter, 2011.

JUNG, C. G. A Prática da Psicoterapia. Petrópolis: Vozes, 1985a. 
. O espírito na arte e na ciência. Petrópolis: Vozes, 1985 b.

. Tipos Pscológicos. Petrópolis: Vozes, 1991.

KLEIN, M. A importância da formação de símbolos no desenvolvimento do ego. In: Contribuições à psicanálise. São Paulo: Ed Mestre Jou, 1970a.

. A personificação no brincar das crianças. In: Contribuições à psicanálise. São Paulo: Ed Mestre Jou, 1970b.

KREISLER, L. A nova criança da desordem psicossomática. São Paulo: Casa do Psicólogo, 1999.

. Criança e seu corpo. Rio de Janeiro, Zahar, 1981.

LOURENÇÃO VAN KOLCK, O. Testes Projetivos Gráficos no Diagnóstico Psicológico. São Paulo: EPU, 1984.

LOURENÇÃO VAN KOLCK, O.; MORAES JAEHN, S. A criança asmática e o desenho da figura humana. Ciência e Cultura,1982, 34(10), 1343-5.

MACEDO DE QUEIROZ, A. Os desajustamentos da criança asmática - uma contribuição à Psicologia Clínica: quanto ao seu conteúdo e às suas técnicas. Revista de Psicologia Normal e Patológica, 1960, 2(3), 363-620.

MACEDO DE QUEIROZ, A.; STRAUSS, A. Contribuições psicológicas à clínica da criança asmática. Revista de Psicologia Normal e Patológica, 1958, IV(8), 83-94.

MAIA, J. G. S. et al. Prevalência de asma e sintomas asmáticos em escolares de 13 e 14 anos de idade. Rev. Saúde Pública [online]. 2004, vol.38, n.2, pp. 292-299. ISSN 0034-8910. http://dx.doi.org/10.1590/S0034-89102004000200020.

MARTY, P. Mentalização e psicossomática. São Paulo, Casa do Psicólogo, 1998. . A Psicossomática do Adulto. Porto Alegre: Artes Médicas, 1993. 
MASTRINER, S.M.M.E. O Procedimento de Desenhos-Estória em Crianças Asmáticas.

Tese de Doutorado. Instituto de Psicologia da Universidade de São Paulo, São Paulo, 1989.

MELLO, F.J. O ser e o viver: uma visão da obra de Winnicott. São Paulo: Casa do Psicólogo, 2001.

NAKANO, T.C. O desenho na expressão criativa: teste de criatividade figural infantil. In:

WECHSLER, S.M.; NAKANO, T,C. (Orgs.) O desenho infantil: forma de expressão cognitiva, criativa e emocional. São Paulo: Casa do Psicólogo, 2012. P.67- 95.

NAKANO,T.C; WECHSLER S. M; PRIMI R. Teste de Criatividade Figural Infantil: TCFI 1 ed. São Paulo: Vetor, 2011.

NERY, C.M.G.; GORDO, A.R.; TRINCA, W. Estudo sobre o psiquismo feminino através de três gerações. In: GUELLER, A.S.; HERMANN, F.; LOWENKRON, T. (Orgs.) Pesquisando com o método psicanalítico. São Paulo: Casa do Psicólogo, 2004, p. 423-429.

NEVES, S.M.R. Breve panorama histórico da psicossomática psicanalítica. In: VOLICH, R.M.; FERRAZ, F.C.; ARANTES, M.A.A.C. (Orgs.). Psicossoma II: Psicossomática Psicanalítica. São Paulo: Casa do Psicólogo, 2007. P. 41-44.

OCAMPO (et all.) O processo psicodiagnóstico e as técnicas projetivas. $-11^{\mathrm{a}} \mathrm{d}$. - São Paulo: Editora WMF Martins Fontes, 2009.

OSTROWER, F. Criatividade e Processos de Criação. Petrópolis: Vozes, 1999.

PARENTE, S.M.B.A. A criação da externalidade do mundo. In: PINTO, M.C.(Org.) Livro de Ouro da Psicanálise. Rio de Janeiro: Ediouro, 2007.

PARSONS, M. A lógica do brincar em psicanálise. In: Livro Anual de Psicanálise, vol. XV, São Pulo: Escuta, 2001.

PEÇANHA, D. L. A reciprocidade de desenvolvimento entre a criança com asma e sua família. São Paulo, tese de Doutorado, USP, 1997. 
PENTEADO, A.F.C. Notas sobre o desenvolvimento do campo da psicossomática da criança. In: VOLICH, R.M.; FERRAZ, F.C.; ARANTES, M.A.A.C. (Orgs.) Psicossoma II: Psicossomática Psicanalítica São Paulo: Casa do Psicólogo, 2007. P. 137-142.

PODKAMENI, A. Metodologia da Pesquisa em Psicossomática Psicanalitica: Algumas Considerações. In: PODKAMENI, A., CAMPOS, E.P., GUIMARÃES, M.A. (Orgs). Winnicott e a pesquisa em psicossomática: um novo olhar. Rio de Janeiro: Publit Soluções Editoriais, 2006. P. 15-25.

RIECHEMANN, J. C. Medicina Psicossomática e Psicologia da Saúde. In: CAMON, V. A. A. (Org.) Psicologia da Saúde: um novo significado para a prática clínica. São Paulo: Pioneira, 2000.

SAFRA, G. Pesquisa com Material Clínico. Revista Psicanálise e Universidade, 1994, no 1 p. 51-71

Procedimentos Clínicos utilizados no Psicodiagnóstico. In: TRINCA,W. Diagnóstico Psicológico, prática clínica. São Paulo: EPU, 1984. P. 51-66.

SCHNEIDER, R. E. F. Uma intervenção com crianças asmáticas a partir do enfoque winnicottiano, 2008, dissertação de mestrado, Universidade do Vale do Rio dos Sinos.

SEGAL, H. Sonho, fantasia e arte. Rio de Janeiro, 1993.

SOCIEDADE BRASILEIRA DE PNEUMOLOGIA E TISIOLOGIA, III CONSENSO BRASILEIRO NO MANEJO DA ASMA, Anais. Jornal de Pneumologia, v.28, supl.1, capítulo I: definição, epidemiologia, patologia e patogenia. São Paulo, Junho de 2002. Disponível em http://www.scielo.br/scielo.php?script=sci_arttext\&pid=S010235862002000700004. Acessado em 18 de setembro de 2010.

SOUZA, A. S. L. Melainie Klein e o brincar levado a sério: rumo à possibilidade de análise com crianças. In: GUELLER, A.S.; SOUZA A.S.L. (Orgs.) Psicanálise com crianças: perspectivas teórico-clínicas. São Paulo: Casa do Psicólogo, 2008. P.123-134. 
SOUZA, F. Problemas psicossomáticos relacionados com o aparelho respiratório. Fator psicógeno na asma brônquica. Jornal Brasileiro de Psiquiatria, 1949, I, 3- 16

SPITZ, R. A. Primeiro ano de vida: um estudo psicanalítico do desenvolvimento normal e anormal das relações objetais. 5 ed. São Paulo, Martins Fontes, 1988.

TAVARES. Marcelo. A Entrevista Clinica. In: CUNHA [et al]. Psicodiagnóstico V. $-5^{\mathrm{a}}$ Ed. Revisada e ampliada - Porto Alegre: Artmed, 2000, pp45-56.

TORRANCE, E.P.; TORRANCE, J.P. Pode-se ensinar criatividade? São Paulo, EPU, 1974.

Criatividade: medidas, testes e avaliação. São Paulo, IBRASA, 1976.

TRINCA, W. (Org.). Formas de Investigação Clínica em Psicologia. São Paulo: Vetor, 1997.

Considerações sobre um modelo de pesquisa em psicanálise. Psychê Revista de Psicanálise, 2002, VI(10), 195-204.

. (org.) Diagnóstico psicológico: a prática clínica. São Paulo: EPU, 1984.

Investigação Clínica da Personalidade: o desenho livre como estímulo de apercepção temática. São Paulo: EPU, 2010 ( $3^{\text {a }}$ edição).

O desenho livre como estímulo de apercepção temática. Tese de Doutorado. São Paulo (SP), Instituto de Psicologia da USP, 1972.

TURATO, E. R. Tratado da metodologia da pesquisa clínico-qualitativa: construção teórico-epistemológica, discussão comparada e aplicação na áreas da saúde e humanas. Petrópolis. RJ: Vozes, 2003.

VILELA, E.M.B.;TRINCA,W. Asma brônquica: uma dimensão psicanalítica. Revista Psychê, 2001, V(7), 119-131. 
WANDALSEN, N.F. et al. Avaliação de critérios para o diagnostico de asma através de um questionário epidemiológico. Jornal Brasileiro de Pneumologia (online). 2009, vol.35, n.3, p. 199-205. http://www.scielo.br/pdf/jbpneu/v35n3/v35n3a02.pdf

WECHSLER, S.M. Avaliação da criatividade por figuras e palavras: teste de Torrance versão brasileira. Campinas: Lamp/Impressão Digital do Brasil, 2002.

. Avaliação multidimensional da criatividade: uma realidade necessária Multidimensional creativity assessment: an urgent reality. Psicol. Esc. Educ. (Impr.) [online]. 1998, vol.2, n.2, pp. 89-99. ISSN 1413-8557. http://dx.doi.org/10.1590/S141385571998000200003.

. Criatividade: descobrindo e encorajando. São Pulo: Psy, 2008.

WEISS, E.; ENGLISH, O.S. Medicina Psicossomática: Aplicação Clinica da Psicopatologia aos Problemas da Clínica Geral. Rio de Janeiro: Editora Guanabara, 1946.

WINNICOTT, D. W. A criança e seu mundo. Rio de Janeiro: LTD, 2008.

. Consultas Terapêuticas. Rio de Janeiro: Imago, 1984.

. Da Pediatria à Psicanálise: obras escolhidas. Rio de Janeiro: Imago, 2000.

. Natureza Humana. Rio de Janeiro: Imago, 1990.

O Brincar e a Realidade. Rio de Janeiro: Imago, 1975.

Os Bebês e suas Mães. São Paulo: Martins Fontes, 2006. 